\title{
Current and future roles of biosimilars in oncology practice (Review)
}

\author{
SOFIA KONSTANTINIDOU, ANGELIKI PAPASPILIOU and ELENI KOKKOTOU
}

Oncology Unit, The Third Department of Medicine, Medical School, National and Kapodistrian University of Athens, 11527 Athens, Greece

Received August 1, 2019; Accepted October 30, 2019

DOI: 10.3892/ol.2019.11105

\begin{abstract}
Biologics have been used increasingly in the treatment and supportive care of cancer; however, their high cost places a significant burden on healthcare systems. The expiration of patents for biologics has led to the development of biosimilars, with the aim of reducing cost and increasing accessibility to novel treatments, which are affordable for a greater number of patients. Biosimilars are highly similar but not identical to the reference products; therefore, strict regulatory requirements have been formed for their approval. This ensures that there are no clinically meaningful differences compared with respective biologics, with regard to purity, safety and efficacy. In 2003, a regulatory framework for the approval of biosimilars was established in Europe, whereas the USA did not implement a framework until 2009, when the Biologics Price Competition and Innovation Act was formed. A number of biosimilars have currently been approved in oncology and the number is expected to rise in the near future. More than 10 years of evidence has revealed that biosimilars are safe and effective; however healthcare professionals need to be further educated to eliminate potential misconceptions and integrate biosimilars into routine clinical practice. The present review aims to provide an overview of the biosimilars used in Europe and the USA, present their main benefits and challenges, and discuss their current and future roles in medical oncology.
\end{abstract}

\section{Contents}

1. Introduction

2. Biologics and biosimilars

3. Biosimilars in oncology

4. Conclusions and future perspectives

Correspondence to: Miss Sofia Konstantinidou, Oncology Unit, The Third Department of Medicine, Medical School, National and Kapodistrian University of Athens, 152 Mesogion, 11527 Athens, Greece

E-mail: sissykonstantinidou@gmail.com

Key words: biosimilars, biologics, oncology, costs, regulatory considerations

\section{Introduction}

In recent years, biologics have increasingly been used for the treatment and palliative care of various diseases, including, but not limited to, cancer, autoimmune diseases, cardiovascular diseases and metabolic disorders $(1,2)$. Biologics are made or derived from a biological source and are typically large complex recombinant proteins, encompassing hormones, small proteins, vaccines, fusion proteins and monoclonal antibodies $(3,4)$.

Biologics account for half of the pharmacological market in oncology; however, their main drawback is their high cost (5). As patents of these biologics began to expire, biosimilars were developed in order to address the existing needs and facilitate access to novel treatments for all patients (6). As compared with biologics, biosimilars are generally cheaper and more affordable; therefore, they have the potential to significantly reduce healthcare costs (7).

The aim of the present review is to provide an overview of the biosimilars used and their respective regulatory requirements in Europe and the USA. In addition, the main benefits and challenges of biosimilars, as well as their current and future roles in the field of medical oncology will be discussed.

\section{Biologics and biosimilars}

Overview and key differences. A biosimilar is defined by the USA Food and Drug Administration (FDA) as a biological product that is highly similar to and has no clinically meaningful differences from an existing FDA-approved reference product in terms of safety, purity and potency (8). Even though biosimilars have identical amino acid sequences to their reference products, they differ in 3D structure, glycosylation sites, isoform profiles and protein aggregation (9). Therefore, pharmacodynamic and pharmacokinetic studies are required to prove their biosimilarity (9). Biosimilars must have the same therapeutic indications, mechanism of action, route of administration, dosage form and strength as the reference product. Some minor differences in clinically inactive components may be allowed, as long as they do not affect the drug safety (10).

In contrast to generics, which are made by chemical synthesis and are exact copies of the reference drug, biosimilars are highly similar with regard to structure, safety, efficacy and immunogenicity, but are not identical to 
the reference product (Table I) (9). Biosimilars and biologics in the European Union (EU) are evaluated using the same requirements and standards, as determined by the European Medicines Agency (EMA) (3). The EU approved the first biosimilar biosimilar in 2015, filgrastim (Zarxio ${ }^{\circledR}$ ), almost a decade later than the somatropin (Omnitrope ${ }^{\circledR}$ ) in 2006, which was followed by the approval of many more (11). Up until 2018, 35 biosimilars have entered the European market, whereas only seven have been licensed in the USA (6). The USA approved the first biosimilar filgrastim $\left(\right.$ Zarxio $\left.^{\circledR}\right)$ in 2015, almost a decade later than the EU and the next one was approved on 2018 (Neupogen ${ }^{\circledR}$ ); however, more are expected to enter the market within the next 2 years (6).

As reported by Cook et al (12) only $26 \%$ of oncologists can explain what a biosimilar is, whereas another study demonstrated that only $21 \%$ of prescribers are familiar with the concept of biosimilars (13). Furthermore, various studies have identified significant gaps in the knowledge of healthcare professionals concerning biosimilars; therefore, it is important to increase awareness and inform professionals that the approval of biosimilars is based on reliable scientific data and clinical trials (14). Both the European Society for Medical Oncology and the American Society of Oncology have developed guidelines to assist healthcare professionals and enhance their confidence in prescribing biosimilars (10). Furthermore, in Australia, a significant effort has been made to alleviate misconceptions regarding biosimilars, with the government spending AU\$20 million on this issue (13).

Regulatory considerations. The World Health Organization recommends that in order to demonstrate biosimilarity between biologics and their respective biosimilars, compatibility and characterization studies must be conducted for comparative evaluation of physicochemical properties, stability, impurities and biological activity (10). Both the FDA and EMA have robust guidelines in order to demonstrate biosimilarity through in vitro and in vivo data (15). To demonstrate bioequivalence, pharmacokinetic and pharmacodynamic studies are required $(1,11)$, as well as safety and efficacy trials to compare safety, efficacy and immunogenicity between biosimilars and the reference products (16). In 2003, the EMA established a framework for the approval of biosimilars in the EU through the Committee for Medicinal Products for Human Use (CHMP), and in 2005 specific guidelines were established (17). In the USA, biologics are regulated under the Biologics Price Competition and Innovation Act (BPCI Act), so as to ensure purity, safety and efficacy of these agents (9). In terms of biosimilars, the FDA is authorized by the Biologics Price Competition and Innovation Act of 2009, which was conducted to eliminate unnecessary studies of biosimilars in humans and animals, resulting in significant savings in cost and time (6). The extrapolation of indications, which is allowed if proven scientifically and in the presence of adequate clinical data, is usually left to clinical judgment $(4,9)$. However, caution is advised prior to extrapolation to different therapeutic areas due to different pathophysiology mechanisms and dosing schedules (18). Global consistency between the regulatory frameworks and approval processes of biosimilars among different countries would facilitate market access, reduce the number of clinical trials, and save time and costs (19).
Benefits and challenges of biosimilars. The use of biosimilars enables patients to access more affordable treatments, as they cost up to $30 \%$ less than their reference products, thus allowing healthcare systems to make significant cost savings (20). Biosimilars also encourage competition among companies, which contributes to the reduction of prices (1). Switching to the latest biosimilars, such as rituximab, etanercept and infliximab, saved the UK National Health System $£ 210$ million in 2017-2018 (3). By 2023, the patents of almost 20 biologics will expire, including bevacizumab and trastuzumab. The patents on herceptin expired in the USA in June 2019 and in Europe in July 2014. In addition, the avastin patent also expired in the USA in July 2019 (3). Each country and each hospital trust decide which biosimilars will be incorporated into their local formulary (21). Despite their significant benefits, biosimilars are also associated with various challenges, including, but not limited to, the possibility of immunogenicity, the concept of interchangeability, the limited level of awareness, acceptance among healthcare professionals and patients regarding their incorporation in clinical practice, the requirement for clinical trial testing prior to their approval, a rigorous regulatory framework limiting the anticipating savings and certain political barriers (11). Various factors impact immunogenicity, such as the structure of the biosimilar, patient characteristics, the route of administration, the dosing schedule and the formulation (22). It is important to select the appropriate end points in clinical trials in order to demonstrate the safety and efficacy of biosimilars and encourage clinicians confidence in their use (11).

In terms of interchangeability, biosimilars are not always considered interchangeable products unless they meet additional rigorous requirements and achieve the same clinical result as the reference product in any patient, without significantly affecting safety and efficacy (23). According to the USA BPCI Act an interchangeable product may be substituted for the reference product by the pharmacist, without the prescriber's consultation (2). Prior to substitution, healthcare professionals and patients should be well educated, in order to closely monitor any adverse events (4). Currently, to the best of our knowledge, there are no biosimilars approved as interchangeable products by the FDA $(2,9)$.

\section{Biosimilars in oncology}

Current status of biosimilars in the real world oncology setting. Currently, the use of biosimilars in oncology practice is constantly evolving as numerous patents on biologic drugs expire. To date, there are only a few approved biosimilars for cancer treatment; however, many more are expected to enter the market soon (Tables II and III). Biosimilars to epoetins and filgrastims are used in cancer for treating chemotherapy-induced anemia and for the prevention and treatment of chemotherapy-induced neutropenia $(24,25)$. The main concern of clinicians upon switching to biosimilars is immunogenicity, as even small changes in the structure of original biologics may cause loss of efficacy and increase the incidence of adverse events. Immunogenicity may also be triggered by impurities, different routes of administration, storage conditions and patient characteristics (16). Furthermore, due to their challenging nature, there are a limited number of studies that have investigated the use of biosimilars in oncology (18). The majority of biosimilarity studies have been performed for 
Table I. Generics vs. biosimilars: Key differences.

\begin{tabular}{|c|c|c|}
\hline Characteristic & Biosimilars & Generics \\
\hline $\begin{array}{l}\text { Chemical structure compared with the } \\
\text { reference molecule }\end{array}$ & $\begin{array}{l}\text { Complex molecules, post-translational } \\
\text { modifications, slight differences in } \\
\text { structure, same primary amino acid } \\
\text { sequence }\end{array}$ & $\begin{array}{l}\text { Simple molecules, well-defined } \\
\text { structure, same amino acid } \\
\text { sequence. }\end{array}$ \\
\hline Immunogenicity & Can be immunogenic & No immunogenic potential \\
\hline Interchangeability & $\begin{array}{l}\text { Additional switching studies required to } \\
\text { fulfill interchangeability requirements }\end{array}$ & $\begin{array}{l}\text { Switchability between generic } \\
\text { and reference product is } \\
\text { ensured. Interchangeability } \\
\text { among generics is not covered. }\end{array}$ \\
\hline Manufacturing process & Complex biotechnological process & $\begin{array}{l}\text { No need for complex modifications, } \\
\text { easy manufacturing. }\end{array}$ \\
\hline Time for marketing approval & $7-8$ years & $2-3$ years \\
\hline Preclinical studies & Required & $\begin{array}{l}\text { Not required, only bioequivalence } \\
\text { studies. }\end{array}$ \\
\hline Storage & Very sensitive, need special conditions & Easy to store, stable. \\
\hline
\end{tabular}

rituximab biosimilars in rheumatoid arthritis, however there are concerns whether these findings can be extrapolated in the oncology setting (18). In order to minimize the associated risks, preclinical studies comparing biosimilars and biologics are required, as well as post-marketing surveillance studies to demonstrate their safety profile in a real world setting and monitor long-term immunogenicity $(14,26)$. Moreover, pharmacovigilance post-marketing and long-term safety data are important to ensure safety and efficacy in the long-term. Monitoring from patients or healthcare professionals includes reporting of any adverse effects, safety concerns or medication errors (27).

Biosimilars in oncology approved by the FDA or EMA. Rituximab. The biosimilar of rituximab was the first monoclonal antibody biosimilar approved in Europe for cancer treatment (18). Rituximab is a genetically engineered chimeric monoclonal antibody, which binds to and inhibits antigen CD20 from binding to its antibodies. CD20 is expressed in $>90 \%$ of B-cell non-Hodgkin's lymphomas and induces cell death via apoptosis (28). Rituximab has been used for the treatment of non-Hodgkin's lymphoma and chronic lymphocytic leukemia (28). Currently, to the best of our knowledge, there are six approved biosimilars to rituximab in Europe; Rixathon and Riximyo by Sandoz GmbH and Truxima, Blitzima, Ritemvia and Rituzena by Celltrion Healthcare Hungary Kft, which were all approved in 2017; two of these have also been approved in the USA; Truxima by Celltrion Inc. and Ruxience by Pfizer, which were approved in 2018 and 2019, respectively $(29,30)$.

Trastuzumab. Ontruzant, produced by Samsung Bioepis, was the first biosimilar to trastuzumab Herceptin approved by the EMA in 2017. Ontruzant can be used as a monotherapy or in combination with chemotherapy or hormone therapy for human epidermal growth factor receptor 2 (HER2)-positive metastatic breast cancer (31). In addition, it can be used for early HER2-positive breast cancer in combination with chemotherapy and for metastatic gastric cancer (32). In 2018, the
EMA approved four more trastuzumab biosimilars; Herzuma (Celltrion Healthcare Hungary Kft.), Kanjinti (Amgen Europe), Trazimera (Pfizer Europe) and Ogivri (Mylan S.A.S.), with the same indications as Ontruzant (33). In 2017, the FDA approved Ogivri $^{\circledR}$ (Mylan), which was the first trastuzumab-dkst biosimilar in the USA. Ogivri has been approved for early breast cancer, metastatic breast cancer and metastatic gastric cancer, in combination with cisplatin and either capecitabine or 5-fluorouracil (34). Four more biosimilars were approved in 2018 and 2019; Herzuma (Celltrion), Ontruzant (Samsung Bioepis), Trazimera (Pfizer) and Kanjinti (Amgen) (33). Trastuzumab binds to HER2, inhibiting ligand-independent HER2 signaling and preventing HER2 activation. Therefore, trastuzumab inhibits the proliferation of tumor cells that overexpress HER2. Furthermore, trastuzumab is a potent mediator of antibody-dependent-cell-mediated cytotoxicity (35).

Bevacizumab. Bevacizumab is a recombinant humanized monoclonal antibody, which binds and inhibits vascular endothelial growth factor (VEGF), thus blocking angiogenesis of new tumors and tumor growth (36). Bevacizumab gained FDA approval in 2004 as a first line treatment in metastatic colorectal cancer in combination with fluorouracil-based chemotherapy (37). In 2017 and 2018, the FDA and EMA, respectively, approved Mvasi (Amgen), the first biosimilar to Avastin (bevacizumab-awwb). Subsequently, in 2019, Zirabev (Pfizer), the second bevacizumab biosimilar, was approved by the EMA and FDA. Mvasi, with different combinations, is approved for various indications, including metastatic colorectal carcinoma; unresectable, locally advanced, recurrent or metastatic non-squamous non-small cell lung cancer; advanced or metastatic renal cell carcinoma; recurrent ovarian, fallopian tube or primary peritoneal cancer; persistent, recurrent or metastatic carcinoma of the uterine cervix; and recurrent glioblastoma (38).

Filgrastim and pegfilgrastrim. Filgrastim is a recombinant granulocyte colony-stimulating factor, which regulates the 
Table II. EMA-approved biosimilars in oncology.

\begin{tabular}{|c|c|c|c|}
\hline Biosimilar & $\begin{array}{l}\text { Reference biologic } \\
\text { (Active substance) }\end{array}$ & Manufacturer & Approval date \\
\hline Alpheon & $\begin{array}{l}\text { Roferon-A (recombinant } \\
\text { human interferon- } \alpha-2 \alpha \text { ) }\end{array}$ & BioPartners GmbH & 05/09/2006 (Refused) \\
\hline Abseamed & Eprex/Erypo (epoetin- $\alpha$ ) & $\begin{array}{l}\text { Medice Arzneimittel } \\
\text { Putter GmbH \& Co. Kg }\end{array}$ & $28 / 08 / 2007$ \\
\hline Binocrit & Eprex/Erypo (epoetin- $\alpha$ ) & Sandoz GmbH & $28 / 08 / 2007$ \\
\hline Epoetin- $\alpha$ hexal & Eprex/Erypo (epoetin- $\alpha$ ) & Hexal Ag & $28 / 08 / 2007$ \\
\hline Retacrit & Eprex/Erypo (epoetin- $\zeta)$ & Hospira UK Limited & $18 / 12 / 2007$ \\
\hline Silapo & Eprex/Erypo (epoetin- $\zeta)$ & Stada Arzneimittel Ag & $18 / 12 / 2007$ \\
\hline Ratiograstim & Neupogen (filgrastim) & Ratiopharm GmbH & $15 / 09 / 2008$ \\
\hline Tevagrastim & Neupogen (filgrastim) & Teva GmbH & $15 / 09 / 2008$ \\
\hline Biograstim & Neupogen (filgrastim) & Abz-Pharma GmbH & 15/09/2008 (withdrawn) \\
\hline Filgrastim ratiopharm & Neupogen (filgrastim) & Ratiopharm GmbH & 15/09/2008 (withdrawn) \\
\hline Zarzio & Neupogen (filgrastim) & Sandoz & $02 / 06 / 2009$ \\
\hline Filgrastim hexal & Neupogen (filgrastim) & Hexal Ag & 02/06/2009 \\
\hline Nivestim & Neupogen (filgrastim) & Hospira UK & 08/06/2010 \\
\hline Grastofil & Neupogen (filgrastim) & Apotex Europe Bv & $18 / 10 / 2013$ \\
\hline Accofil & Neupogen (filgrastim) & Accord Healthcare Ltd & $18 / 09 / 2014$ \\
\hline Truxima & MabThera (rituximab) & Celltrion Healthcare Hungary Kft. & $17 / 02 / 2017$ \\
\hline Riximyo & MabThera (rituximab) & Sandoz GmbH & $15 / 06 / 2017$ \\
\hline Rixathon & MabThera (rituximab) & Sandoz GmbH & $15 / 06 / 2017$ \\
\hline $\begin{array}{l}\text { Rituzena } \\
\text { (previously Tuxella) }\end{array}$ & MabThera (rituximab) & Celltrion Healthcare Hungary Kft. & $\begin{array}{l}\text { 13/07/2017 (approved) } \\
\text { 12/05/2019 (withdrawn) }\end{array}$ \\
\hline Ritemvia & MabThera (rituximab) & Celltrion Healthcare Hungary Kft. & $13 / 07 / 2017$ \\
\hline Blitzima & MabThera (rituximab) & Celltrion Healthcare Hungary Kft. & $13 / 07 / 2017$ \\
\hline Ontruzant & Herceptin (trastuzumab) & Samsung Bioepis & $17 / 11 / 2017$ \\
\hline Mvasi & Avastin (bevacizumab) & Amgen Europe B.V. & $14 / 01 / 2018$ \\
\hline Herzuma & Herceptin (trastuzumab) & Celltrion Healthcare Hungary Kft. & $09 / 02 / 2018$ \\
\hline Kanjinti & Herceptin (trastuzumab) & Amgen Europe & $16 / 05 / 2018$ \\
\hline Trazimera & Herceptin (trastuzumab) & Pfizer Europe & $26 / 07 / 2018$ \\
\hline Pelgraz & Neulasta (pegfilgrastim) & Accord Healthcare Limited & $25 / 09 / 2018$ \\
\hline Udenyca & Neulasta (pegfilgrastim) & Coherus & $25 / 09 / 2018$ \\
\hline Fulphila & Neulasta (pegfilgrastim) & Mylan S.A.S. & $20 / 11 / 2018$ \\
\hline Pelmeg & Neulasta (pegfilgrastim) & Cinfa Biotech S.L. & $20 / 11 / 2018$ \\
\hline Ziextenzo & Neulasta (pegfilgrastim) & Sandoz GmbH & $22 / 11 / 2018$ \\
\hline Ogivri & Herceptin (trastuzumab) & Mylan S.A.S. & $12 / 12 / 2018$ \\
\hline Zirabev & Avastin (bevacizumab) & Pfizer Europe & $14 / 02 / 2019$ \\
\hline
\end{tabular}

production of neutrophils from the bone marrow. Filgrastim markedly increases peripheral blood neutrophil counts within $24 \mathrm{~h}$, causing few increases in monocytes (39). Filgrastim can be used to reduce the incidence and duration of febrile neutropenia in patients with non-myeloid malignancies receiving myelosuppressive anticancer drugs or myeloablative therapy followed by bone marrow transplantation. In addition, it can be used for the reduction of time to neutrophil recovery and fever duration in patients with acute myeloid leukemia receiving induction of consolidation chemotherapy (25). Since 2008 and the approval of the first biosimilar of filgrastim by the EMA, eight more biosimilars have been approved in Europe, including Accofil, Biograstim, Filgrastim Hexal, Filgrastim ratiopharm, Grastofil,
Nivestim, Ratiograstim, Tevegrastim and Zarzio. Additionally, two have been approved in the USA; Zarxio (2015) and Nivestym (2018). Compared with filgrastim, pegfilgrastim has an additional polyethylene glycol unit, which increases the size of the molecule and thus increases the half-life. In Europe there are five approved pegfilgrastim biosimilars; Pelgraz, Udenyca, Fulphila, Pelmeg and Ziextenzo. Whereas in the USA, only Udenyca and Fulphila have been approved in 2018.

Epoetins. Epoetin and darbepoetin are similar to the hormone erythropoietin, which is secreted by the kidneys to stimulate red blood cell production (erythropoiesis) in the bone marrow (40). These drugs are also known as erythropoiesis-stimulating 
Table III. FDA-approved biosimilars in oncology.

\begin{tabular}{llll}
\hline Biosimilar & Reference biologic (Active substance) & Manufacturer & FDAapproval date \\
\hline Zarxio & Neypogen (filgrastim-sndz) & Sandoz Inc. & $06 / 03 / 2015$ \\
Mvasi & Avastin (bevacizumab-awwb) & Amgen, Inc. & $14 / 09 / 2017$ \\
Ogivri & Herceptin (trastuzumab-dkst) & Mylan & $01 / 12 / 2017$ \\
Retacrit & Epogen (epoetin alfa-epbx) & Hospira Inc. & $15 / 05 / 2018$ \\
Fulphila & Neulasta (pegfligrastim-jmdb) & Mylan/Biocon & $04 / 06 / 2018$ \\
Nivestym & Neupogen (filgrastim-aafi) & Pfizer Inc. & $20 / 07 / 2018$ \\
Udenyca & Neulasta (pegfligrastim-cbqv) & Coherus Biosciences & $02 / 11 / 2018$ \\
Truxima & Rituxan (rituximab-abbs) & Celltrion Inc. & $28 / 11 / 2018$ \\
Herzuma & Herceptin (trastuzumab-pkrb) & Celltrion Inc. & $18 / 12 / 2018$ \\
Ontruzant & Herceptin (trastuzumab-dttb) & Samsung Bioepis & $18 / 01 / 2019$ \\
Trazimera & Herceptin (trastuzumab-qyyp) & Pfizer Ind. & $11 / 03 / 2019$ \\
Kanjinti & Herceptin (trastuzumab-anns) & Amgen Inc. & $13 / 06 / 2019$ \\
Zirabev & Avastin (bevacizumab-bvzr) & Pfizer Inc. & $28 / 06 / 2019$ \\
Ruxience & Rituxan (rituximab-pvvr) & Pfizer Inc. & $23 / 07 / 2019$ \\
\hline
\end{tabular}

agents (ESAs) and are often used to treat anemia induced by chemotherapy, thus reducing the need for blood transfusions (41). ESAs are considered to be well-tolerated in patients (42). In Europe, there are three epoetin- $\alpha$ (EPO- $\alpha$ ) biosimilars; Abseamed, Binocrit and Epoetin- $\alpha$ hexal, and two epoetin- $\zeta$ biosimilars; Retacrit and Silapo, which were all approved in 2007. By contrast, in the USA, only Retacrit (Hospira, Inc.) has been approved. EPO- $\alpha$ has been approved for the treatment of chemotherapy-induced and symptomatic anemia in patients receiving chemotherapy for solid tumors, malignant lymphoma or multiple myeloma (24). Epoetin- $\zeta$ has the same therapeutic indications as EPO- $\alpha$; however, EPO- $\alpha$ has a higher efficacy due to its different conformational structure (43).

Recombinant human interferon- $\alpha-2 a$. Interferons are a group of signaling proteins that are produced by the body to help fight infections, such as viruses. Roferon-A, a biological molecule, can be used for the treatment of chronic phase Philadelphia-chromosome positive myelogenous leukemia, hairy cell leukemia, cutaneous T-cell lymphoma, follicular non-Hodgkin's lymphoma, advanced renal cell carcinoma and American Joint Committee on Cancer stage II malignant melanoma (38). Alpheon, a biosimilar produced by BioPartners $\mathrm{GmbH}$ in 2006, was refused a marketing authorization by the EMA CHMP due to major differences between the two drugs, inadequate stability data of the active substance and the candidate drug, and increased side effects (44).

Costs of biologic therapy in oncology. Evidence shows that biosimilars offer significant cost savings to the healthcare system. In the USA, due to the loss of patents of many biologics by 2020 , which have a global expenditure of more than $\$ 20$ billion, biosimilars are expected to play a major role in the market (9). However, due to the rigorous requirements of development, manufacturing and licensing, the cost savings are not as much as seen for generic drugs; $15-30 \%$ for biosimilars vs. $80 \%$ for generics, respectively, since the latter require less rigorous clinical trial testing prior to their approval $(26,45)$. However, even though the cost savings associated with the use of biosimilars are less than that for generic drugs, they are still significant. A $20 \%$ reduction in the price of six off-patent biologics would save $€ 1.6$ billion, which would expand patient access to more treatments (46). In Europe, the biosimilar erythropoietin costs $25-30 \%$ less than the original biologic (11). A study reported that by switching to an erythropoietin biosimilar in patients with chemotherapy-induced anemia, vast savings were accomplished, thus enabling additional treatments with rituximab $(9,770$ treatments), bevacizumab (3,912 treatments) and trastuzumab (3,713 treatments) (47). Another cost-analysis study in Europe, predicted that switching to a rituximab biosimilar would save $€ 56.82$ million over a year (10). However, the cost-saving potential depends on various factors, such as the price of the reference product and the competition market (11). The highest savings expected are those associated with biosimilars of anti-tumor necrosis factors drugs (11).

\section{Conclusions and future perspectives}

Biologics are widely used therapeutic agents in the treatment and palliative care of cancer. However, due to their high cost, crises in healthcare spending worldwide and the expiration of biologics patents, biosimilars have come to the market. Biosimilars are more affordable drugs, but with a similar safety and toxicity profile and no clinically meaningful differences compared with their reference biologics. Therefore, biosimilars enable a reduction in healthcare costs and increase a patients' access to novel treatment options. The current underuse of biosimilars in clinical practice may, at least partly, be attributed to a lack of awareness among patients and clinicians regarding the benefits and challenges of biosimilars. Rigorous regulation frameworks and close post-marketing surveillance of licensed biosimilars are required to ensure that these new drugs are safe and effective in the real world setting. Furthermore, health care professionals and the public should be properly educated on the multiple aspects of biosimilars, 
so as to ensure their successful incorporation in routine oncology care.

\section{Acknowledgements}

Not applicable.

\section{Funding}

No funding was received.

\section{Availability of data and materials}

Not applicable.

\section{Authors' contributions}

SK conceived and designed the review. SK, AP and EK performed the literature review. All authors were involved in the preparation and revision of the manuscript.

\section{Ethics approval and consent to participate}

Not applicable.

\section{Patient consent for publication}

Not applicable.

\section{Competing interests}

The authors declare that they have no competing interests.

\section{Authors' information}

Miss Sofia Konstantinidou is an Onassis Foundation Scholar.

\section{References}

1. Zelenetz AD: Biosimilars in oncology. Oncol Hematol Rev 12: $22-28,2016$

2. Campen CJ: Integrating biosimilars into oncology practice: Implications for the advanced practitioner. J Adv Pract Oncol 8 : 688-699, 2017.

3. Robinson J: Ten things pharmacists should know about biologics and biosimilars. Pharmaceutical J: Oct 8,2018 (Epub ahead of print).

4. Tabernero J, Vyas M, Giuliani R, Arnold D, Cardoso F, Casali PG, Cervantes A, Eggermont AM, Eniu A, Jassem J, et al: Biosimilars: A position paper of the European Society for Medical Oncology, with particular reference to oncology prescribers. ESMO Open 1: e000142, 2017.

5. Mellstedt $\mathrm{H}$ : Clinical consideration for biosimilar antibodies. EJC Suppl 11: 1-11, 2013

6. Patel KB, Arantes LH Jr, Tang WY and Fung S: The role of biosimilars in value-based oncology care. Cancer Manag Res 10: 4591-4602, 2018.

7. Chan JC and Chan AT: Biologics and biosimilars: What, why and how? ESMO Open 2: e000180, 2017.

8. Kaida-Yip F, Deshpande K, Saran T and Vyas D: Biosimilars: Review of current applications, obstacles, and their future in medicine. World J Clin Cases 6: 161-166, 2018.

9. Lyman GH: Emerging opportunities and challenges of biosimilars in oncology practice. J Oncol Pract 13 (Suppl 9): 7s-9s, 2017

10. Janjigian YY, Bissig M, Curigliano G, Coppola J and Latymer M: Talking to patients about biosimilars. Future Oncol 14 2403-2414, 2018.
11. Chopra R and Lopes G: Improving access to cancer treatments: The role of biosimilars. J Glob Oncol 3: 596-610, 2017.

12. Cook JW, McGrath MK, Dixon MD, Switchenko JM, Harvey RD and Pentz RD: Academic oncology clinicians' understanding of biosimilars and information needed before prescribing. Ther Adv Med Oncol: Jan 6, 2019 (Epub ahead of print). doi: $10.1177 / 1758835918818335$.

13. Zalcberg J: Biosimilars are coming: Ready or not. Intern Med J 48: 1027-1034, 2018.

14. Rugo HS, Rifkin RM, Declerck P, Bair AH and Morgan G: Demystifying biosimilars: Development, regulation and clinical use. Future Oncol 15: 777-790, 2019.

15. Coiffier B: Preparing for a new generation of biologic therapies: Understanding the development and potential of biosimilar cancer therapeutics. Future Oncol 13: 1-3, 2017.

16. Karalis VD: From bioequivalence to biosi.milarity: The rise of a novel regulatory framework. Drug Res (Stuttg) 66: 1-6, 2016.

17. Harston A: How the U.S. Compares to Europe on Biosimilar Approvals and Products in the Pipeline. Rothwell Figg: May 1, 2019.

18. Declerck P,Bakalos G,Zintzaras E, Barton B and Schreitmüller T: Monoclonal antibody biosimilars in oncology: Critical appraisal of available data on switching. Clin Ther 40: 798-809.e2, 2018.

19. Cazap E, Jacobs I, McBride A, Popovian R and Sikora K: Global acceptance of biosimilars: Importance of regulatory consistency, education, and trust. Oncologist 23: 1188-1198, 2018.

20. Lucio SD, Stevenson JG and Hoffman JM: Biosimilars: Implications for health-system pharmacists. Am J Health Syst Pharm 70: 2004-2017, 2013.

21. Alnahar S, Elliott RA and Smith MD: Biosimilar uptake by British local formularies: A cross sectional study. Int J Clin Pharm 39: 1055-1060, 2017.

22. Farhat F, Torres A, Park W, de Lima Lopes G, Mudad R, Ikpeazu C and Abi Aad S: The concept of Biosimilars: From characterization to Evolution-A narrative review. Oncologist 23: 346-352, 2018

23. Azevedo V,DörnerT, Strohal R,Isaacs J, Castañeda-Hernández G, Gonçalves J and McInnes I: Biosimilars: Considerations for clinical practice. Considerations Med 1: 13-18, 2017.

24. Aapro M, Krendyukov A, Schiestl M and Gascón P: Epoetin Biosimilars in the treatment of chemotherapy-induced anemia: 10 years' experience gained. BioDrugs 32: 129-135, 2018.

25. Ludwig H, Bokemeyer C, Aapro M, Boccadoro M, Gascón P, Denhaerynck K, Krendyukov A, Abraham I and MacDonald K: Chemotherapy-induced neutropenia/febrile neutropenia prophylaxis with biosimilar filgrastim in solid tumors versus hematological malignancies: MONITOR-GCSF study. Future Oncol 15: 897-907, 2019.

26. Aapro M: Biosimilars in oncology: Current and future perspectives. Gen Biosimilars Initiative J (GaBI Journal) 2: 91-93, 2013.

27. Nabhan C, Valley A and Feinberg BA: Barriers to oncology biosimilars uptake in the United States. Oncologist 23: 1261-1265, 2018.

28. Greenwald M, Tesser J and Sewell KL: Biosimilars have arrived: Rituximab. Arthritis 2018: 3762864, 2018.

29. European Generic medicines Association. The future of pharmaceuticals: Generic medicines enhancing pharmaceutical competition and ensuring healthcare sustainability issues. 2007 http://198.170.119.137/doc/ega_FuturePharmaceuticals.pdf. Accessed Jan 12, 2019.

30. US FDA: FDA approves Truxima as biosimilar to Rituxan for non-Hodgkin's lymphoma. 2018. https://www.fda. gov/Drugs/InformationOnDrugs/ApprovedDrugs/ucm627035.htm. Accessed Jan 15, 2019.

31. Pimentel FF, Morgan G, Tiezzi DG and de Andrade JM: Development of new formulations of Biologics: Expectations, immunogenicity, and safety for subcutaneous trastuzumab. Pharmaceut Med 32: 319-325, 2018.

32. US FDA: Drug Approval Package: Ontruzant (trastuzumab-dttb). 2019. https://ww w.accessdata.fda.gov/drugsatfda docs/nda/2019/761100Orig1s000TOC.cfm. Accessed Jan 18, 2019.

33. Uifălean A, Ilieş M, Nicoară R, Rus LM, Hegheş SC and Iuga CA: Concepts and challenges of Biosimilars in breast cancer: The emergence of trastuzumab biosimilars. Pharmaceutics 10: E168, 2018.

34. US FDA: Drug Approval Package: OGIVRI (trastuzumab-dkst). 2017. https://www.accessdata.fda.gov/drugsatfda docs/nda/2017/761074Orig1s000TOC.cfm. Accessed Dec 1, 2017 
35. Rajasekaran N, Chester C, Yonezawa A, Zhao X and Kohrt HE: Enhancement of antibody-dependent cell mediated cytotoxicity: A new era in cancer treatment. Immunotargets Ther 4: 91-100, 2015.

36. Syrigos KN: Bevacizumab in Lung Cancer: Impact and Exceptional Cases. Focus on Health Ltd. Publications, Athens, pp9-11, 2013.

37. Grapsa D, Syrigos K and Saif MW: Bevacizumab in combination with fluoropyrimidine-irinotecan- or fluoropyrimidine-oxaliplatin-based chemotherapy for first-line and maintenance treatment of metastatic colorectal cancer. Expert Rev Anticancer Ther 15: 1267-1281, 2015

38. Casak SJ, Lemery SJ, Chung J, Fuchs C, Schrieber SJ, Chow ECY, Yuan W, Rodriguez L, Gwise T, Rowzee A, et al: FDA's approval of the first biosimilar to bevacizumab. Clin Cancer Res 15: 4365-4370, 2018

39. Aapro M, Bokemeyer C, Ludwig H, Gascón P, Boccadoro M, Denhaerynck K, Gorray M, Krendyukov A, MacDonald K and Abraham I: Chemotherapy-induced (febrile) neutropenia prophylaxis with biosimilar filgrastim in elderly versus non-elderly cancer patients: Patterns, outcomes, and determinants (MONITOR-GCSF study). J Geriatr Oncol 8: 86-95, 2017.

40. Jelkmann W: Physiology and pharmacology of erythropoietin Transfus Med Hemother 40: 302-309, 2013.

41. Tonelli M, Hemmelgarn B, Reiman T, Manns B, Reaume MN Lloyd A, Wiebe N and Klarenbach S: Benefits and harms of erythropoiesis-stimulating agents for anemia related to cancer: A meta-analysis. CMAJ 180: E62-E71, 2009.

42. Xirou V, Gkiozos I, Grapsa D, Dimitroulis I and Syrigos K: P2.01-039 Erythropoiesis-stimulating agents for chemotherapy-induced anaemia in lung cancer: Efficacy, toxicity and effect on survival. J Thorac Oncol 12 (Suppl 2): S2084, 2017.
43. Irrera N, Bitto A, Pizzino G, Vaccaro M, Squadrito F, Galeano M, Stagno d'Alcontres F, Stagno d'Alcontres F, Buemi M, Minutoli L, et al: Epoetin alpha and Epoetin zeta: A comparative study on stimulation of angiogenesis and wound repair in an experimental model of burn injury. Biomed Res Int 2015: 968927, 2015.

44. Smeeding J, Malone DC, Ramchandani M, Stolshek B, Green L and Schneider P: Biosimilars: Considerations for Payers. PT 44: 54-63, 2019.

45. Simoens S: Biosimilar medicines and cost-effectiveness. Clinicoecon Outcomes Res 3: 29-36, 2011.

46. European Generic medicines Association. The future of pharmaceuticals: Generic medicines enhancing pharmaceutical competition and ensuring healthcare sustainability issues. 2007. http://198.170.119.137/doc/ega_FuturePharmaceuticals.pdf. Accessed Feb 1, 2019.

47. Abraham I, Han L, Sun D, MacDonald K and Aapro M: Cost savings from anemia management with biosimilar epoetin alfa and increased access to targeted antineoplastic treatment: A simulation for the EU G5 countries. Future Oncol 10: 1599-1609, 2014.

(i) (3) This work is licensed under a Creative Commons Attribution-NonCommercial-NoDerivatives 4.0 International (CC BY-NC-ND 4.0) License. 